\title{
La responsabilité de la formation professionnelle incombe désormais à l'ISFM
}

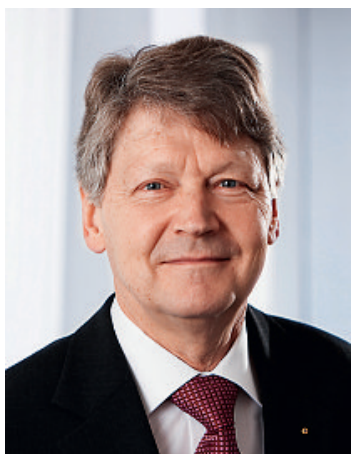

Max Giger
L'Institut suisse pour la formation médicale postgraduée et continue, ISFM en abrégé, a succédé à la Commission pour la formation postgraduée et continue (CFPC) au $1^{\text {er }}$ avril 2009 [1]. L'ensemble du domaine de la formation postgraduée placé sous l'égide de la FMH est désormais autonome dans le cadre de ce nouvel institut. La formation professionnelle des médecins s'est ainsi enfin affranchie des intérêts tarifaires et de politique professionnelle pour se consacrer essentiellement aux besoins de la population. Au sein de la FMH, l'ISFM rend compte directement à la Chambre médicale.

C'est avec un nouvel élan que la FMH met en œuvre les tâches que lui a confiées le Département fédéral de l'intérieur (DFI) dans le domaine de la formation postgraduée des médecins [2]. Les travaux en vue de l'accréditation à venir se font dans les délais impartis et la qualité de la formation postgra-

\section{Dans le cadre de I'ISFM, la formation professionnelle des médecins est désormais autonome}

duée est assurée au moyen d'instruments internationalement reconnus. Selon la devise «l'évaluation stimule la formation», nous travaillons intensément à l'élaboration d'une évaluation centrée sur le lieu de travail assortie d'un retour d'informations, qui structurera la formation postgraduée pratique et permettra une nouvelle culture de communication. La formation des formateurs dans les hôpitaux et les cabinets médicaux sera également étendue.

La formation continue va elle aussi de l'avant. Ainsi, nous avons pu lancer le grand projet de «plate-forme de formation continue». Celle-ci permettra aux médecins, au moyen d'un portfolio de formation continue, d'accomplir la formation professionnelle exigée par la Loi sur les professions médicales (LPMéd) de manière plus efficace et ainsi d'améliorer l'efficacité de la formation continue.

\section{L'évaluation centrée sur le lieu de}

travail structurera la formation postgraduée et permettra une nouvelle culture de communication

De nouveaux défis se posent: la formation d'effectifs médicaux suffisants tant sur le plan qualitatif que quantitatif, ainsi que la garantie du financement de la formation postgraduée sous le système DRG. Les objectifs de formation postgraduée et continue définis dans la LPMéd doivent être pensés et appliqués sur le long terme. En font partie, outre les objectifs scientifiques propres à chaque discipline, notamment la collaboration interdisciplinaire avec d'autres professions, la capacité à collaborer avec d'autres médecins et professionnels de la santé, ainsi qu'à accompagner les patients jusqu'à la fin de leur existence.

La création de l'ISFM permet de renforcer l'image de la formation professionnelle des médecins, qui est à la base de tout acte médical, et aussi le garant de sa qualité.

Dr Max Giger, président de l'ISFM

\section{Références}

1 Hänggeli Ch, Giger M. L'institut Suisse pour la formation médicale postgraduée ISFM se présente. Bull Méd Suisses. 2009;90(26/27):1029-33.

2 Giger M, Hänggeli Ch. ISFM: principaux projets. Bull Méd Suisses. 2009;90(26/27):1034-36. 